\title{
Strain-Induced Ferroelectric Heterostructure Catalysts of Hydrogen Production through Piezophototronic and Piezoelectrocatalytic System
}

Authors: Syuan-Lin Guo ${ }^{1}$, Sz-Nian Lai ${ }^{1}$, and Jyh Ming $\mathrm{Wu}^{1,2 *}$

[*] Prof. J. M. Wu

${ }^{1}$ Department of Materials Science and Engineering, National Tsing Hua University

101, Section 2 Kuang Fu Road, Hsinchu 300, Taiwan.

${ }^{2}$ High Entropy Materials Center, National Tsing Hua University, 101, Section 2 Kuang

Fu Road, Hsinchu 300, Taiwan.

*Corresponding author: wujm@mx.nthu.edu.tw

\section{Supporting Information of S1: X-ray diffraction patterns}

The XRD patterns in Figure S1 are composed of patterns A, B, C, D, and E. Pattern A belongs to a hexagonal $\mathrm{MoSe}_{2}$ (JCPDS Card No. 29-0914). ${ }^{1}$ The pattern B presents the $\mathrm{TiO}_{2}$ nanoparticles (NPs) consisting of $30 \%$ of the rutile and $70 \%$ of the anatase phase. The peaks at the $2 \Theta=27.4^{\circ}, 36.08^{\circ}$, and $41.2^{\circ}$ indicated the rutile phases (JCPDS Card No. 21-1276), ${ }^{2}$ and the other peaks are identified as the anatase phases (JCPDS Card No. 21-1272). ${ }^{2}$ The pattern $\mathrm{C}$ consists of $\mathrm{TiO}_{2}$ and $\mathrm{MoSe}_{2}$ compounds. The (100) plane of $\mathrm{MoSe}_{2}$ can be observed at the $2 \Theta \approx 31.8^{\circ}$. The weakened (100) plane of $\mathrm{MoSe}_{2}$ is primarily owing to the few-layered $\mathrm{MoSe}_{2}$ NSs. The second phase of $\mathrm{SeO}_{2}$ (JCPDS Card No. 22-1314) was also observed. ${ }^{3}$ The pattern D is attributed to the $\mathrm{BaTiO}_{3}$ microparticles (MPs), which belongs to the tetragonal structure (JCPDS Card No. 05-0626). ${ }^{3}$ Pattern E consists of BTO and $\mathrm{MoSe}_{2}$ compounds. The peaks of $\mathrm{MoSe}_{2}$ NSs have overlapped with BTO MPs. The diffraction peaks with weaker intensities of $\mathrm{MoSe}_{2}$ NSs did not significantly observe, demonstrating the highly dispersed singleand few-layered $\mathrm{MoSe}_{2}$ NSs. Besides, an additional peak around $2 \Theta \approx 26.5^{\circ}$, 
indicating that the $\mathrm{BaMoO}_{4}$ (JCPDS Card No. 29-0193) was formed during the hydrothermal process. ${ }^{4,5,6}$

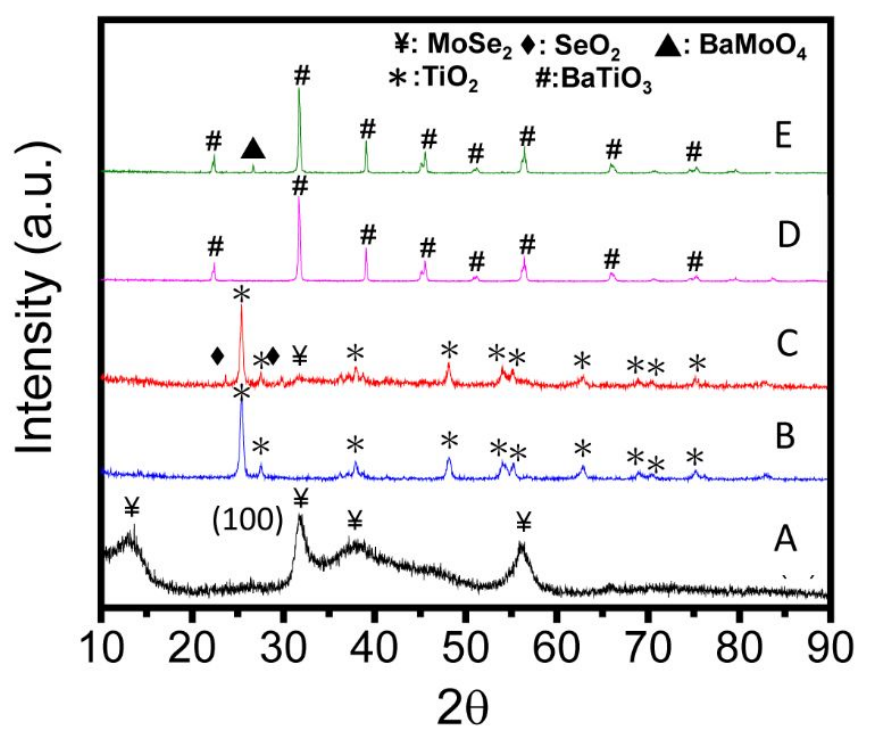

Figure S1. XRD patterns of (A) $\mathrm{MoSe}_{2} \mathrm{NSs},(\mathrm{B}) \mathrm{TiO}_{2} \mathrm{NPs},(\mathrm{C}) \mathrm{TiO}_{2} @ \mathrm{MoSe}_{2} \mathrm{NSs}$, (D) $\mathrm{BaTiO}_{3} \mathrm{MPs}$, and (E) BTO@MoSe $\mathrm{MSs}_{2}$

\section{Supporting Information of S2: X-ray photoelectron spectroscopy (XPS)}

XPS was employed to analyze the compositions and chemical states of $\mathrm{TiO}_{2} @ \mathrm{MoSe}_{2}$ and BTO@MoSe $\mathrm{MSs}_{2}$ Figure S2a shows the two Ti 2p peaks in $\mathrm{TiO}_{2}$ NPs, which are the spin-orbital splitting of $\mathrm{Ti}^{4+}$. The two peaks located at $458.4 \mathrm{eV}$ and $464.1 \mathrm{eV}$, corresponding to the $2 \mathrm{p}_{3 / 2}$ and $2 \mathrm{p}_{1 / 2}$, respectively. ${ }^{7}$ Compared to the $\mathrm{TiO}_{2} \mathrm{NPs}$, the Ti $2 \mathrm{p}_{3 / 2}$ and $2 \mathrm{p}_{1 / 2}$ peaks of the $\mathrm{TiO}_{2} @ \mathrm{MoSe}_{2}$ NSs have shifted towards higher binding energies at 459 and $464.7 \mathrm{eV}$, respectively, revealing the strong interaction between $\mathrm{TiO}_{2}$ and $\mathrm{MoSe}_{2}{ }^{8}$ Figure $2 \mathrm{~b}$ shows that the $\mathrm{O}$ 1s peak in $\mathrm{TiO}_{2} \mathrm{NPs}$ can be deconvoluted into 529.8 and $531.7 \mathrm{eV}$, attributed to the Ti-O and hydroxide bonds ($\mathrm{OH})$ on the surface of $\mathrm{TiO}_{2}$, respectively. ${ }^{7}$ As for the $\mathrm{TiO}_{2} @ \mathrm{MoSe}_{2}$ NSs, the peak of Ti-O was shifted to $530.3 \mathrm{eV}$. An additional peak at $529.7 \mathrm{eV}$ is ascribed to the Mo-O bonding. Figure 2c shows the Mo 3d peaks in $\mathrm{MoSe}_{2} \mathrm{NSs}$. The $\mathrm{Mo}^{4+}$ peaks at $229.5 \mathrm{eV}$ 
and $232.6 \mathrm{eV}$ are corresponded to the $3 \mathrm{~d}_{5 / 2}$ and $3 \mathrm{~d}_{3 / 2}$, respectively. ${ }^{9}$ Similarly, the Mo $3 \mathrm{~d}_{5 / 2}$ and $\mathrm{Mo} 3 \mathrm{~d}_{5 / 2}$ in $\mathrm{TiO}_{2} @ \mathrm{MoSe}_{2}$ NSs shifted towards the lower energy at $228.7 \mathrm{eV}$ and $231.8 \mathrm{eV}$. There are two additional peaks at the $232.9 \mathrm{eV}$ and $236 \mathrm{eV}$ associated with the $\mathrm{MoO}_{3},{ }^{8}$ indicating that the binding energy of oxygen-molybdenum in $\mathrm{TiO}_{2} @ \mathrm{MoSe}_{2} \mathrm{NSs}$ brought to the steady-state of oxidated interfaces. Figure S2d reveals that the $3 \mathrm{~d}_{5 / 2}$ and $3 \mathrm{~d}_{3 / 2}$ peaks, ${ }^{9}$ corresponding to $54.6 \mathrm{eV}$ and $55.5 \mathrm{eV}$ in $\mathrm{MoS}_{2}$ NSs are the reduction state of $\mathrm{Se}^{2+}$. These peaks have shifted to lower energy at 54.4 and 55.3 eV for $\mathrm{TiO}_{2} @ \mathrm{MoSe}_{2} \mathrm{NSs}$. The shifts in the XPS peaks are related to its oxidation state and bonding energy with strain effect, implying that the heterostructure TiO $\mathrm{T}_{2} @ \mathrm{MoSe}_{2}$ NSs formed strong chemical bonds. ${ }^{10} 11$ As shown in Figure 2e, the peaks at binding energy $778 \mathrm{eV}$ and $793.3 \mathrm{eV}$ can be assigned to $\mathrm{Ba} 3 \mathrm{~d}_{5 / 2}$ and $3 \mathrm{~d}_{3 / 2}$ core lines of $\mathrm{Ba}^{2+} .{ }^{12}$, 13 The peaks at $3 \mathrm{~d}_{5 / 2}$ and $3 \mathrm{~d}_{3 / 2}$ peaks in BTO@MoSe 2 NSs have shifted to the higher binding energy of $778.9 \mathrm{eV}$ and $794.2 \mathrm{eV}$, respectively. Figure $2 \mathrm{f}$ reveals that the $\mathrm{Ti}^{4+}$ of $\mathrm{BaTiO}_{3}$ microparticles (MPs) composed of $2 \mathrm{p}_{3 / 2}$ and $2 \mathrm{p}_{1 / 2}$, which positioned at 457.4 $\mathrm{eV}$ and $463 \mathrm{eV} .{ }^{14}$ Similarly, for the BTO@MoSe 2 NSs, the $2 \mathrm{p}_{3 / 2}$ and $2 \mathrm{p}_{1 / 2}$ peaks have shift to the higher binding energy of $458.7 \mathrm{eV}$ and $464.5 \mathrm{eV}$, respectively.

The O1s peaks in BTO can be deconvoluted into three peaks at 528.5, 530.2, and $531.8 \mathrm{eV}$, associated with the Ti-O, Ba-O, and $\mathrm{O}-\mathrm{H}$ bonds, respectively, as shown in Figure S2g. ${ }^{15}$ As for the BTO@MoSe ${ }_{2}$ NSs, these peaks were shifted to higher binding energies, positioned at 529.86, 530.7, and $532.3 \mathrm{eV}$. The other peak appears at 528.8 $\mathrm{eV}$, attributed to the molybdenum-oxygen bonds, indicating that $\mathrm{MoSe}_{2} \mathrm{NSs}$ were grown on the BTO crystals by Mo-O bonds. Similarly, as shown in Figure S2h, the binding energy of BTO@MoSe $\mathrm{MSs}_{2}$ at $228.9 \mathrm{eV}$ and $231.8 \mathrm{eV}$ correspond to the $\mathrm{Mo}^{4+}$ $3 d 5 / 2$ and $3 d_{3 / 2}$, respectively, and they have shifted to lower binding energy compared with the pristine $\mathrm{MoSe}_{2}$ NSs. The peak at $233 \mathrm{eV}$ and $235.7 \mathrm{eV}$ are attributed to $\mathrm{Mo}^{6+}$ 
owing to the formation of the $\mathrm{MoO}_{3}$ compound. As shown in Figure S2i, the binding energy of Se 3d for BTO@MoSe $\mathrm{MSs}_{2}$ can be deconvoluted into the Se 3d $\mathrm{d}_{5 / 2}$ and Se $3 \mathrm{~d}_{3 / 2}$, which corresponding to the binding energy of $54.5 \mathrm{eV}$ and $55.4 \mathrm{eV}$, respectively. The binding energy of Se 3d for $\mathrm{BaTiO}_{3} @ \mathrm{MoSe}_{2}$ NSs has shifted to lower energies compared with the pristine $\mathrm{MoSe}_{2}$ NSs. The binding energies of $\mathrm{Ba} 3 \mathrm{~d}$, Ti $2 \mathrm{p}$, and $\mathrm{O} 1 \mathrm{~s}$ in $\mathrm{BaTiO}_{3} @ \mathrm{MoSe}_{2} \mathrm{NSs}$ have shifted to higher energies, which implies that $\mathrm{BaTiO}_{3}$ MPs act as the electron donor. By contrast, Mo 3d and Se 3d in $\mathrm{BaTiO}_{3} @ \mathrm{MoSe}_{2} \mathrm{NSs}$ have shifted to lower energies, indicated that $\mathrm{MoSe}_{2}$ nanosheets act as the electron acceptor to form the $p$ - $n$ junction ferroelectric/piezoelectric composites. ${ }^{16}$
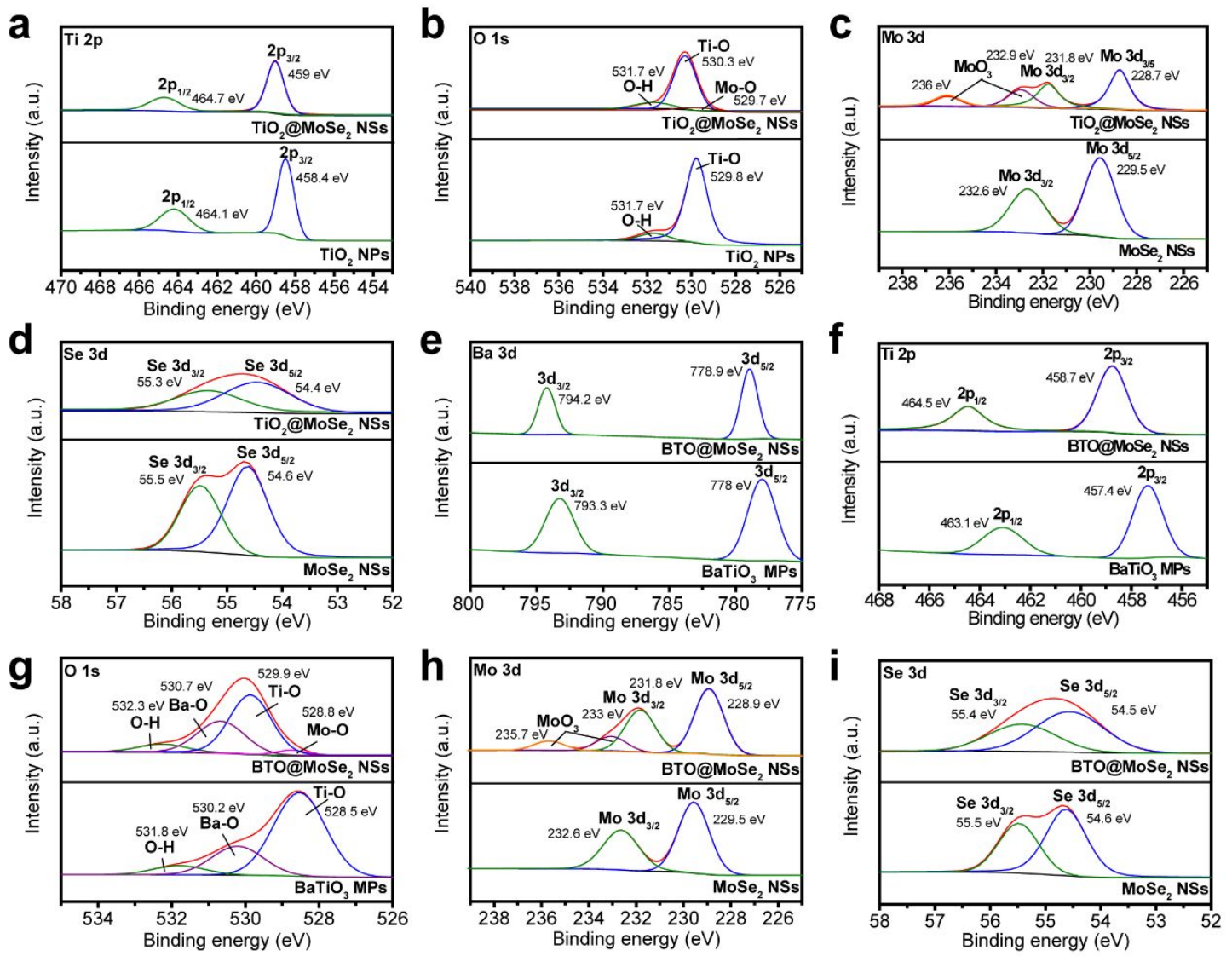

Figure S2. XPS spectra of $\mathrm{TiO}_{2} \mathrm{NPs}, \mathrm{BaTiO}_{3} \mathrm{MPs}, \mathrm{MoSe}_{2} \mathrm{NSs}, \mathrm{TiO}_{2} @ \mathrm{MoSe}_{2}$, and BTO@MoSe ${ }_{2}$ NSs for (a) Ti 2p, (b) O 1s, (c) Mo 3d, (d) Se 3d, (e) Ba 3d, (f) Ti 2p, (g) O 1s, (h) Mo 3d, and (i) Se 3d. 
Table. S1 Comparison of hydrogen evolution reaction.

\begin{tabular}{|c|c|c|c|c|}
\hline Catalyst & Type & Driven source & $\begin{array}{c}\mathrm{H}_{2} \text {-Production } \\
\text { rate } \\
\left(\mu \mathrm{mol} \cdot \mathrm{g}^{-1} \mathrm{~h}^{-1}\right)\end{array}$ & References \\
\hline$\overline{\mathrm{BTO} @ \mathrm{MoSe}_{2}}$ & Piezoelectrocatalyst & $\begin{array}{l}\text { Ultrasonic-wave } \\
\qquad(300 \mathrm{~W})\end{array}$ & 4533 & This study \\
\hline $\begin{array}{c}2 \mathrm{D} \\
\mathrm{Ni}_{2} \mathrm{P} @ \mathrm{BP} / \mathrm{CN}\end{array}$ & Photocatalyst & Xe lamp (300 W) & 858.2 & 17 \\
\hline $\mathrm{MoS}_{2} / \mathrm{g}-\mathrm{C}_{3} \mathrm{~N}_{4}$ & Photocatalyst & Xe lamp (300 W) & 577 & 18 \\
\hline $1 \mathrm{~T}-\mathrm{MoSe}_{2} / \mathrm{C}_{3} \mathrm{~N}_{4}$ & Photocatalyst & Xe lamp (300 W) & 1672.6 & 19 \\
\hline GSH-MoS 2 & Piezocatalyst & $\begin{array}{l}\text { Ultrasonic-wave } \\
\qquad(280 \mathrm{~W})\end{array}$ & 1250 & 20 \\
\hline $\mathrm{KNbO}_{3} / \mathrm{MoS}_{2}$ & Piezophotocatalyst & $\begin{array}{l}\text { Xe lamp (300 W) } \\
\text { Ultrasonic-wave }\end{array}$ & 96 & 21 \\
\hline CdS nanosheets & Piezophotocatalyst & $\begin{array}{l}\text { Xe lamp }(300 \mathrm{~W}) \\
\text { Ultrasonic-wave } \\
(100 \mathrm{~W})\end{array}$ & 633 & 22 \\
\hline $\mathrm{KNbO}_{3} / \mathrm{MoS}_{2}$ & Piezophotocatalyst & $\begin{array}{l}\text { Xe lamp (300 W) } \\
\text { Ultrasonic-wave }\end{array}$ & 305 & 23 \\
\hline
\end{tabular}


a

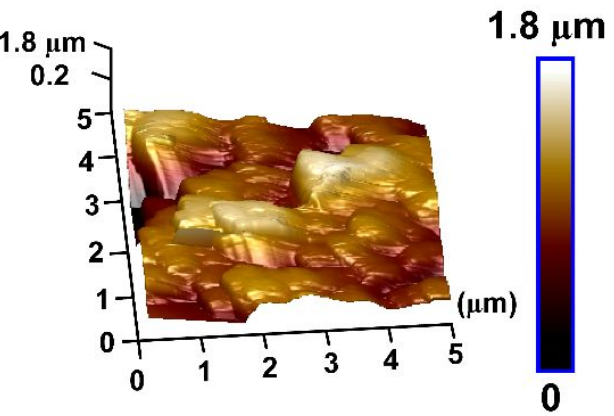

b $\quad 49.7 \mathrm{mV}$

20.4

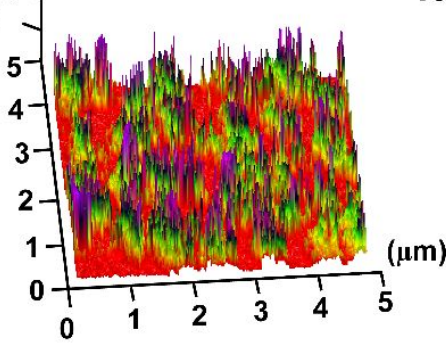

$49.7 \mathrm{mV}$

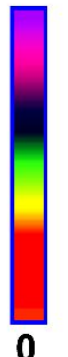

Figure S3. (a) Height sensor images of $\mathrm{MoSe}_{2} \mathrm{NFs}$, and (b) the piezoelectric potential outputs of $\mathrm{MoSe}_{2} \mathrm{NFs}$.

Supporting information of S3: Hall Measurement and energy levels of heterostructure catalysts

The carrier concentration of the $\mathrm{TiO}_{2}, \mathrm{MoSe}_{2}$, and BTO are $-2.74 \times 10^{15}, 2.26 \times$ $10^{15}$, and $-6.89 \times 10^{15} \mathrm{~cm}^{-3}$ respectively, confirming $\mathrm{TiO}_{2}$ and $\mathrm{BTO}$ are $n$-type semiconductors while the $\mathrm{MoSe}_{2}$ belongs to $p$-type semiconductor, which led to forming the $p$ - $n$ junction $\mathrm{TiO}_{2} @ \mathrm{MoSe}_{2}$ and $\mathrm{BTO} @ \mathrm{MoSe}_{2}$ nanocomposites. The carrier mobility of $\mathrm{TiO}_{2} \mathrm{NPs}, \mathrm{MoSe}_{2} \mathrm{NSs}$, and $\mathrm{BaTiO}_{3} \mathrm{MPs}$ are 43, 41, and $1.23 \mathrm{~cm}^{2} \mathrm{~V}^{-1} \mathrm{~s}^{-1}$, respectively. ${ }^{24,25}$ The energy level of the $p$ - $n$ junction heterostructure catalysts is shown in Figure S4. ${ }^{24-26}$

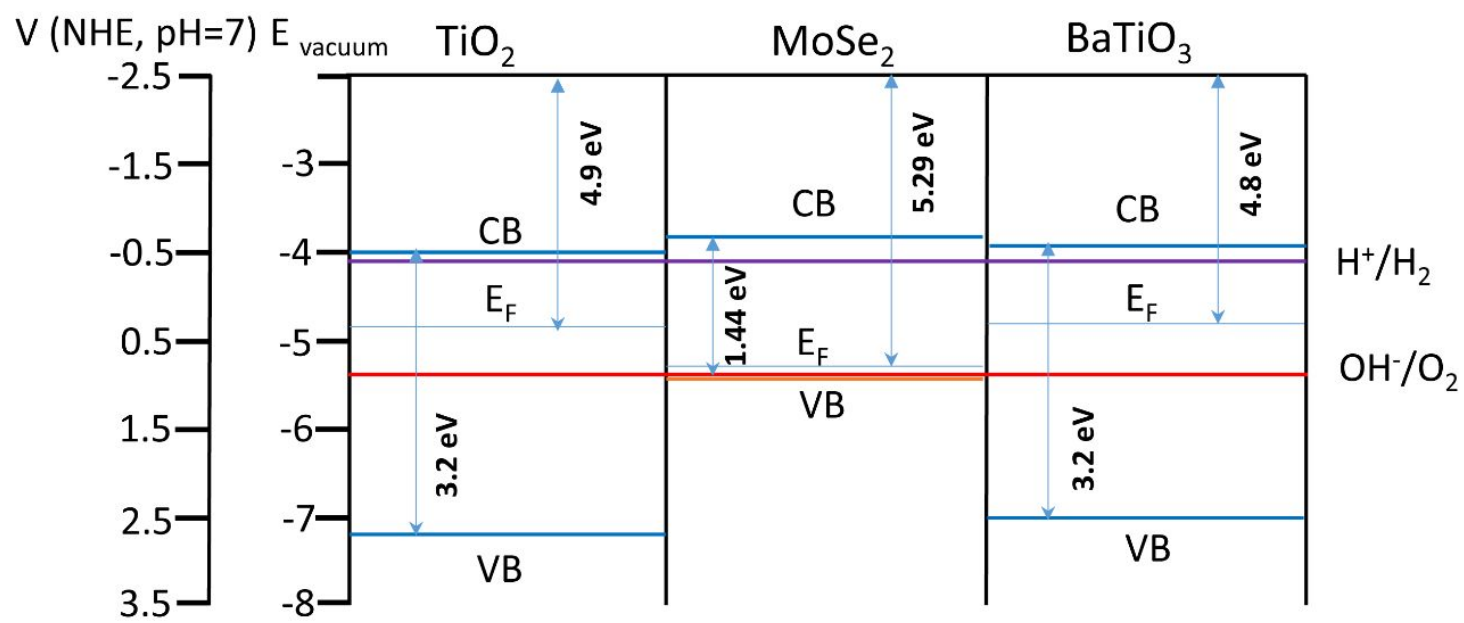

Figure S4. Schematic of energy band levels of $\mathrm{TiO}_{2} \mathrm{NPs}, \mathrm{MoSe}_{2}$, and $\mathrm{BaTiO}_{3} .{ }^{27}, 28$ Supporting information of S4: 
The direction of piezoelectric polarization of $\mathrm{MoSe}_{2}$ pointed to the right side. The negative piezopotential was established at the interface (Figure S5a), and the corresponding simulated polarization field streamlines (Figure S5b) indicated that electrons diffused to the right side while the hole migrated to the left side.

a

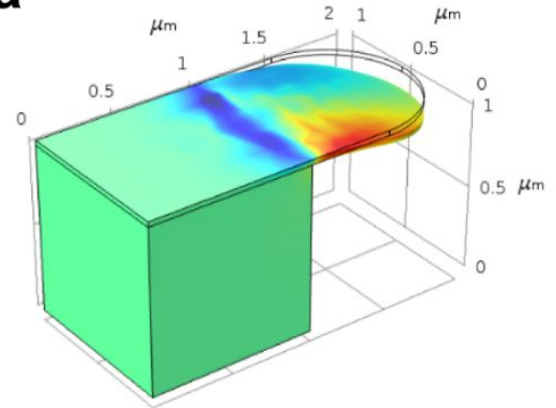

b

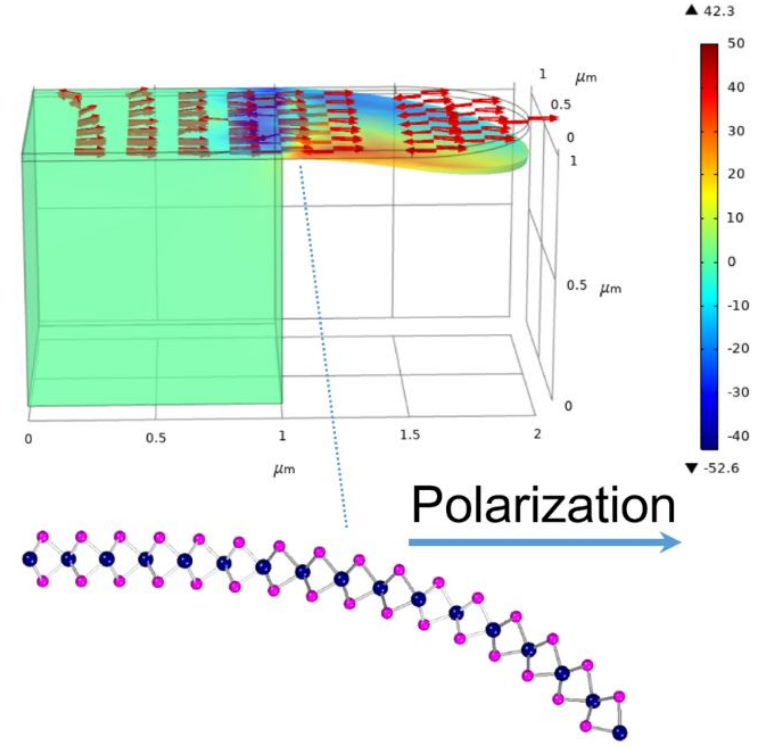

Figure S5. (a) When the $\mathrm{MoSe}_{2}$ nanosheet was downward bending along with the -zaxis, the negative piezopotential (unit: Voltage, V) forms at the interface. (b) The simulated polarization field streamlines indicated that electrons diffused to the right side while hole migrated to the left side.

\section{Supporting information of S5:}

The dielectric tensor of $\mathrm{BaTiO}_{3}$ and $\mathrm{MoSe}_{2}$ are shown in Equ. (1) and (2), respectively 29

$\varepsilon_{\mathrm{BaTiO}_{3}}=\left[\begin{array}{ccc}2920 & 0 & 0 \\ 0 & 2920 & 0 \\ 0 & 0 & 168\end{array}\right]$

$\varepsilon_{\mathrm{MoSe}_{2}}=\left[\begin{array}{ccc}6.9 & 0 & 0 \\ 0 & 6.9 & 0 \\ 0 & 0 & 1.4\end{array}\right]$

The stiffness tensor of $\mathrm{BaTiO}_{3}$ and $\mathrm{MoSe}_{2}$ are shown in Equ. (3) and (4), respectively. (unit: GPa) 


$$
\begin{aligned}
s_{\mathrm{BaTiO}_{3}} & =\left[\begin{array}{cccccc}
275.1 & 178.9 & 151.5 & 0 & 0 & 0 \\
178.9 & 275.1 & 151.5 & 0 & 0 & 0 \\
151.5 & 151.5 & 164.8 & 0 & 0 & 0 \\
0 & 0 & 0 & 54.3 & 0 & 0 \\
0 & 0 & 0 & 0 & 54.3 & 0 \\
0 & 0 & 0 & 0 & 0 & 113.1
\end{array}\right] \\
S_{\mathrm{MoSe}_{2}} & =\left[\begin{array}{cccccc}
65 & 18 & 4 & 0 & 0 & 0 \\
18 & 65 & 4 & 0 & 0 & 0 \\
4 & 4 & 4 & 0 & 0 & 0 \\
0 & 0 & 0 & 2 & 0 & 0 \\
0 & 0 & 0 & 0 & 2 & 0 \\
0 & 0 & 0 & 0 & 0 & 24
\end{array}\right]
\end{aligned}
$$

The piezoelectric tensors of BTO and $\mathrm{MoSe}_{2}$ are expressed in Equ. (5) and (6), respectively. ${ }^{29,30}$

$$
\begin{aligned}
d_{\mathrm{BaTiO}_{3}} & =\left[\begin{array}{cccccc}
0 & 0 & 0 & 0 & 392 & 0 \\
0 & 0 & 0 & 392 & 0 & 0 \\
-34.5 & -34.5 & 85.6 & 0 & 0 & 0
\end{array}\right] \\
d_{\mathrm{MoSe}_{2}} & =\left[\begin{array}{cccccc}
4.7 & -4.7 & 0 & 0 & 0 & 0 \\
0 & 0 & 0 & 0 & 0 & -9.4 \\
0 & 0 & 0 & 0 & 0 & 0
\end{array}\right]
\end{aligned}
$$

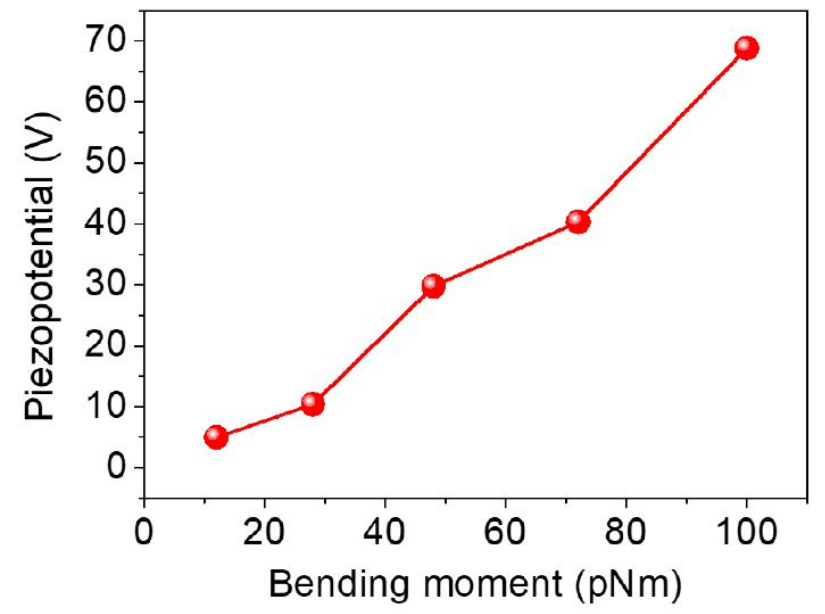

Figure S6. An increase in the bending moment of $\mathrm{MoSe}_{2}$ was directly proportional to the piezopotential when the mechanical force was applied along the z-direction.

\section{Supporting information of S7:}

When a force was applied at the free end of the $\mathrm{MoSe}_{2} \mathrm{NSs}$ in the $-z$-direction, the 
$\mathrm{MoSe}_{2} \mathrm{NSs}$ experienced tensile and compressive stresses on the top and bottom, respectively (top image, Figure S7a). FEM simulation results in Figure S7a (lower image) show that the piezoelectric polarization field's gradient driven the electron and hole to diffuse in the opposite direction. For simplification, the piezoelectric polarization of $\mathrm{BTO}$ and $\mathrm{MoSe}_{2}$ was individually considered. Considering the piezoelectric polarization of $\mathrm{MoSe}_{2} \mathrm{NSs}$, Figure S7b illustrates that the negative piezopotential $\left(\phi_{p}^{n}\right)$ established at the interface between BTO and $\mathrm{MoSe}_{2}$ to generate a polarization field gradient and drive holes flowing from the $\mathrm{MoSe}_{2}$ to the BTO part and accumulated at the interface. Meanwhile, electrons were migrated in the opposite direction. By contrast, for considering the piezoelectric polarization of the $n$-type BTO. FEM result (Figure S7c) reveals that the polarization field gradient was created in BTO, indicated that holes diffused from the left to the right side and accumulated at the interface because of the positive piezopotential $\left(\phi_{p}^{p}\right)$ established at the interface (Figure S7d). We simultaneously considered two simulation cases for both BTO and $\mathrm{MoSe}_{2}$ NSs with the opposite piezoelectric polarization directions. FEM result (Figure S7e) showed that combination of piezoelectric polarization from both BTO and $\mathrm{MoSe}_{2} \mathrm{NSs}$ was contributed to a negative piezopotential at the interface, which driven the migration of holes from both sides of BTO and $\mathrm{MoSe}_{2}$ and accumulated at the interface, and the electrons migrated to both sides to proceed with the oxidation and reduction reactions, respectively, as shown in Figure S7f. 


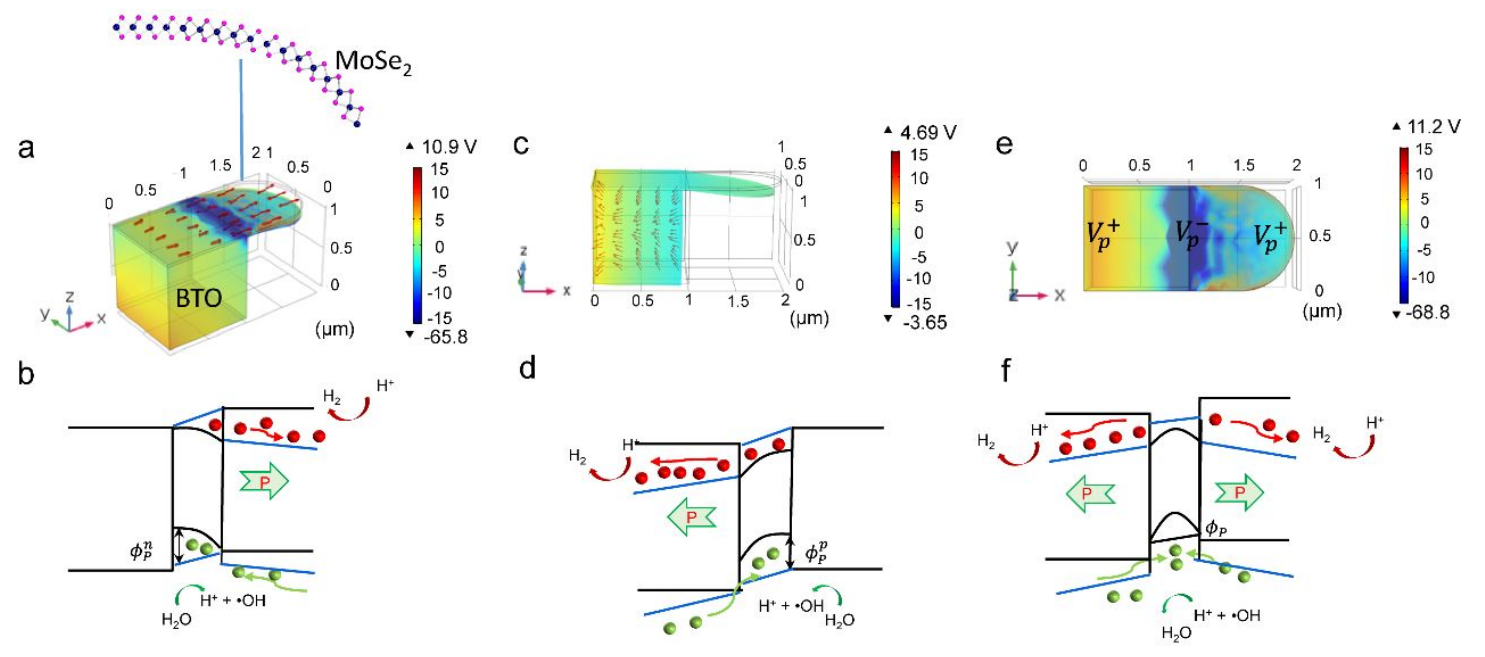

Figure S7. (a) For considering the piezoelectric polarization of $\mathrm{MoSe}_{2} \mathrm{NS}$. A force was applied at the free end of the cantilever beam of $\mathrm{MoSe}_{2} \mathrm{NSs}$ along the -z-direction. The corresponding $p-n$ junction band structure and the negative piezopotential forms at the interfacial region. (b) The corresponding $p$ - $n$ band structure shows that the holes were migrated from right to left side in $\mathrm{MoSe}_{2}$ to accumulate at the interface, while electrons diffuse in the opposite direction. (c) Considering the piezoelectric polarization of BTO, the positive piezopotential was established at the interfacial region. (d) The corresponding $p-n$ band structure shows that the piezopotential forms at the interface, driven the holes to migrate from left to right side in BTO and accumulate at the interface, while the electrons diffuse in the opposite direction. (e) Considering the piezoelectric polarization for both $\mathrm{BTO}$ and $\mathrm{MoSe}_{2}$. The corresponding $p$ - $n$ band structure established the negative piezopotential at the interface, and positive piezopotential on both sides, (f), which drove the electron to diffuse to both sides of BTO and $\mathrm{MoSe}_{2}$ while holes were accumulated at the interface.

\section{Supporting information of S8:}

Based on the finite element method (FEM) calculated by COMSOL Multiphysics, we need to consider the electrical displacement of the material. The mechanical forceinduced electrical displacement is strongly related to the distribution of the elastic 
matrix. Therefore, FEM calculates the piezoelectric potential distribution, expressed by stress-charge form, as given by Equ. (1)-(3). ${ }^{31}$

Stress-charge from:

$\sigma=\mathrm{C}_{\mathrm{E}} \square-\mathrm{e}^{\mathrm{T}} \mathrm{E}$

$\mathrm{D}=\mathrm{e} \varepsilon+\varepsilon_{0} \varepsilon_{\mathrm{rS}} \mathrm{E}$

The stress-charge form is used in the variational formulation, which uses for discretization and computation by COMSOL Multiphysics. Where $\sigma$ is the stress, $\mathrm{C}_{\mathrm{E}}$ is the elastic matrix, $\square$ is the strain, $\mathrm{E}$ is the electrical field, D is the electric displacement, $e$ is the piezoelectric coupling (electrical field/stress). $\varepsilon_{0}$ is the permittivity of the vacuum. $\varepsilon_{\mathrm{rS}}$ denoted relative permittivity. The electric field is computed from the electric potential $\mathrm{V}$ as

$\mathrm{E}=-\nabla \mathrm{V}$ 


\section{References:}

1. Balasingam, S. K.; Lee, J. S.; Jun, Y., Few-Layered $\mathrm{MoSe}_{2}$ Nanosheets as an Advanced Electrode Material for Supercapacitors. Dalton Trans. 2015, 44, 1549115498.

2. Scarpelli, F.; Mastropietro, T.; Poerio, T.; Godbert, N., Mesoporous $\mathrm{TiO}_{2}$ Thin Films: State of the Art. Titanium Dioxide - Material for a Sustainable Environment. IntechOpen: London, 2018, 57-80.

3. Vidojković, V. M.; Branković, A. R.; Milošević, S. D., Mechanical Activation of $\left(\mathrm{SeO}_{2}+\mathrm{Na}_{2} \mathrm{CO}_{3}\right)$ Mixture and Sodium Selenite Synthesis. Mater. Lett. 1997, 31, 5560.

4. Diffract, P., File, JCPDS Internat. Centre. Diffract. Data, PA 2004, 19073, 3273.

5. Luo, Z.; Li, H.; Shu, H.; Wang, K.; Xia, J.; Yan, Y., Synthesis of $\mathrm{BaMoO}_{4}$ Nestlike Nanostructures under a New Growth Mechanism. Cryst. Growth Des. 2008, 8, 22752281.

6. Wang, Y.; Li, M.; Pan, K.; Wang, G., Synthesis and Novel Luminescence Properties of One-Dimension $\mathrm{BaMoO}_{4}: \mathrm{Ln}^{3+}$ Nanostructures. Mater. Res. Bull. 2015, $72,269-275$.

7. Erdem, B.; Hunsicker, R. A.; Simmons, G. W.; Sudol, E. D.; Dimonie, V. L.; ElAasser, M. S., XPS and FTIR Surface Characterization of $\mathrm{TiO}_{2}$ Particles Used in Polymer Encapsulation. Langmuir 2001, 17, 2664-2669.

8. Wu, H.; Wu, Y.; Chen, X.; Ma, Y.; Xu, M.; Wei, W.; Pan, J.; Xiong, X., Rational Design and Preparation of Few-Layered $\mathrm{MoSe}_{2}$ Nanosheet@C/TiO 2 Nanobelt Heterostructures with Superior Lithium Storage Performance. RSC Advances 2016, 6, 23161-23168.

9. Zhao, Y.; Lee, H.; Choi, W.; Fei, W.; Lee, C. J., Large-Area Synthesis of 
Monolayer $\mathrm{MoSe}_{2}$ Films on $\mathrm{SiO}_{2} / \mathrm{Si}$ Substrates by Atmospheric Pressure Chemical Vapor Deposition. RSC Advances 2017, 7, 27969-27973.

10. Xu, F.; Zhu, B.; Cheng, B.; Yu, J.; Xu, J., 1D/2D $\mathrm{TiO}_{2} / \mathrm{MoS}_{2}$ Hybrid Nanostructures for Enhanced Photocatalytic $\mathrm{CO}_{2}$ Reduction. Adv. Opt. Mater. 2018, 6, 1800911.

11. Chen, G.; Song, X.; Guan, L.; Chai, J.; Zhang, H.; Wang, S.; Pan, J.; Tao, J., Defect Assisted Coupling of a $\mathrm{MoS}_{2} / \mathrm{TiO}_{2}$ Interface and Tuning of Its Electronic Structure. Nanotechnology 2016, 27, 355203.

12. Yuan, D. C.; Guo, S.; Hou, S. H.; Ma, Y. J.; Wang, J. L.; Wang, S. F., Enhanced Thermoelectric Performance of C-Axis-Oriented Epitaxial Ba-Doped BiCuSeO Thin Films. Nanoscale Res. Lett. 2018, 13.

13. Miot, C.; Husson, E.; Proust, C.; Erre, R.; Coutures, J., Residual Carbon Evolution in $\mathrm{BaTiO}_{3}$ Ceramics Studied by XPS after Ion Etching. J. Eur. Ceram. Soc. 1998, 18, 339-343.

14. Nithya, P.; Devi, L. G., Heavy Atom Perturbation by the Incorporation of Iodine Ion into $\mathrm{BaTiO}_{3}$ Lattice: Reduction of Fluorescence and Enhancement of Rate of Interfacial Charge Transfer Process under the Visible Light Irradiation. Surf. Interfaces 2020, $18,100411$.

15. Devi, L. G.; Nithya, P., Photocatalytic Activity of Hemin (Fe(III) Porphyrin) Anchored $\mathrm{BaTiO}_{3}$ under the Illumination of Visible Light: Synergetic Effects of Photosensitization, Photo-Fenton and Photocatalysis Processes. Inorg. Chem. Front 2018, 5, 127-138.

16. Wei, T. C.; Lau, W. M.; An, X. Q.; Yu, X. L., Interfacial Charge Transfer in $\mathrm{MoS}_{2} / \mathrm{TiO}_{2}$ Heterostructured Photocatalysts: The Impact of Crystal Facets and Defects. Molecules 2019, 24. 
17. Boppella, R.; Yang, W.; Tan, J.; Kwon, H.-C.; Park, J.; Moon, J., Black Phosphorus Supported $\mathrm{Ni}_{2} \mathrm{P}$ Co-Catalyst on Graphitic Carbon Nitride Enabling Simultaneous Boosting Charge Separation and Surface Reaction. Appl. Catal. B: Environmental 2019, 242, 422-430.

18. Liu, Y.; Zhang, H.; Ke, J.; Zhang, J.; Tian, W.; Xu, X.; Duan, X.; Sun, H.; Tade, M. O.; Wang, S., 0D $\mathrm{MoS}_{2} / 2 \mathrm{D}\left(\mathrm{g}-\mathrm{C}_{3} \mathrm{~N}_{4}\right)$ Heterojunctions in Z-Scheme for Enhanced Photocatalytic and Electrochemical Hydrogen Evolution. Appl. Catal. B: Environmental 2018, 228, 64-74.

19. Yi, J.; Li, H.; Gong, Y.; She, X.; Song, Y.; Xu, Y.; Deng, J.; Yuan, S.; Xu, H.; Li, H., Phase and Interlayer Effect of Transition Metal Dichalcogenide Cocatalyst toward Photocatalytic Hydrogen Evolution: The Case of $\mathrm{MoSe}_{2}$. Appl. Catal. B: Environmental 2019, 243, 330-336.

20. Su, Y.; Zhang, L.; Wang, W.; Li, X.; Zhang, Y.; Shao, D., Enhanced $\mathrm{H}_{2}$ Evolution Based on Ultrasound-Assisted Piezo-Catalysis of Modified $\mathrm{MoS}_{2}$. J. Mater. Chem. A 2018, 6, 11909-11915.

21. Jia, S.; Su, Y.; Zhang, B.; Zhao, Z.; Li, S.; Zhang, Y.; Li, P.; Xu, M.; Ren, R., Few-layer $\mathrm{MoS}_{2}$ Nanosheet-Coated $\mathrm{KNbO}_{3}$ Nanowire Heterostructures: PiezoPhotocatalytic Effect Enhanced Hydrogen Production and Organic Pollutant Degradation. Nanoscale 2019, 11, 7690-7700.

22. Zhao, Y.; Huang, X. Y.; Gao, F.; Zhang, L. L.; Tian, Q. F.; Fang, Z. B.; Liu, P., Study on Water Splitting Characteristics of CdS Nanosheets Driven by the Coupling Effect between Photocatalysis and Piezoelectricity. Nanoscale 2019, 11, 9085-9090.

23. Jia, S. F.; Su, Y. P.; Zhang, B. P.; Zhao, Z. C.; Li, S.; Zhang, Y. F.; Li, P. C.; Xu, M. Y.; Ren, R., Few-Layer $\mathrm{MoS}_{2}$ Nanosheet-Coated $\mathrm{KNbO}_{3}$ Nanowire Heterostructures: Piezo-Photocatalytic Effect Enhanced Hydrogen Production and 
Organic Pollutant Degradation. Nanoscale 2019, 11, 7690-7700.

24. Schulmeyer, T.; Paniagua, S. A.; Veneman, P. A.; Jones, S. C.; Hotchkiss, P. J.; Mudalige, A.; Pemberton, J. E.; Marder, S. R.; Armstrong, N. R., Modification of $\mathrm{BaTiO}_{3}$ Thin Films: Adjustment of the Effective Surface Work Function. J. Mater. Chem. 2007, 17, 4563-4570.

25. Marques, F. C.; Jasieniak, J. J., Ionization Potential and Electron Attenuation Length of Titanium Dioxide Deposited by Atomic Layer Deposition Determined by Photoelectron Spectroscopy in Air. Appl. Surf. Sci. 2017, 422, 504-508.

26. Borodin, A.; Reichling, M., Characterizing $\mathrm{TiO}_{2}(110)$ Surface States by Their Work Function. Phys. Chem. Chem. Phys. 2011, 13, 15442-15447.

27. Li, X.; Jia, G.; Du, J.; Song, X.; Xia, C.; Wei, Z.; Li, J., Type-II InSe/MoSe $2\left(\mathrm{WSe}_{2}\right)$ van der Waals Heterostructures: Vertical Strain and Electric Field Effects. J. Mater. Chem. C 2018, 6, 10010-10019.

28. Fujisawa, J.-i.; Eda, T.; Hanaya, M., Comparative Study of Conduction-Band and Valence-Band Edges of $\mathrm{TiO}_{2}, \mathrm{SrTiO}_{3}$, and $\mathrm{BaTiO}_{3}$ by Ionization Potential Measurements. Chem. Phys. Lett. 2017, 685, 23-26.

29. Li, Z.; Chan, S. K.; Grimsditch, M.; Zouboulis, E., The Elastic and Electromechanical Properties of Tetragonal $\mathrm{BaTiO}_{3}$ Single Crystals. Int. J. Appl. Phys. 1991, 70, 7327-7332.

30. Duerloo, K.-A. N.; Ong, M. T.; Reed, E. J., Intrinsic Piezoelectricity in TwoDimensional Materials. J. Phys. Chem. Lett. 2012, 3, 2871-2876.

31. Zhang, Y.; Liu, Y.; Wang, Z. L., Fundamental Theory of Piezotronics. Adv Mater 2011, 23, 3004-3013. 
